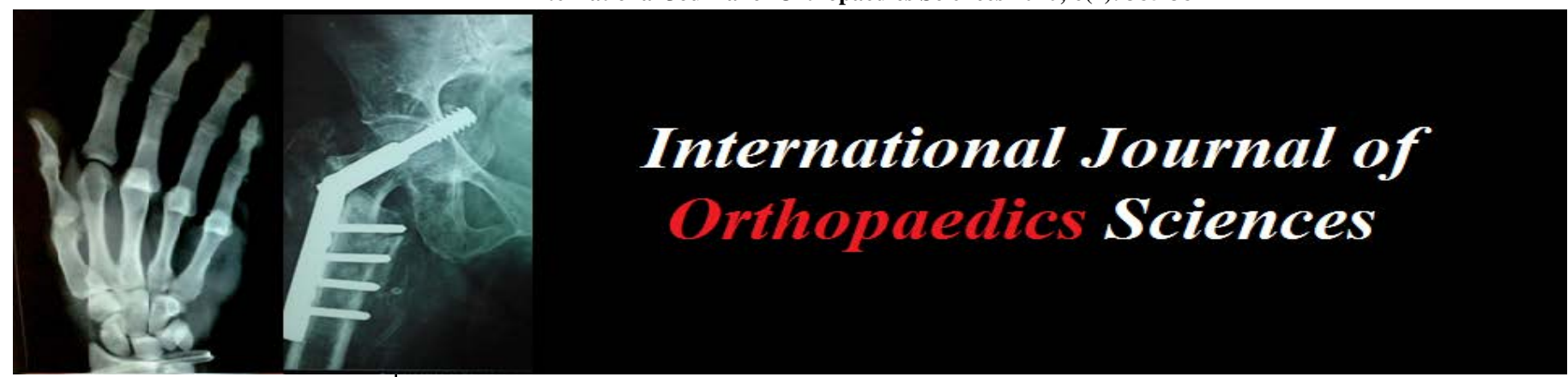

E-ISSN: 2395-1958

P-ISSN: 2706-6630

IJOS 2020; 6(4): 385-387

(C) 2020 IJOS

www.orthopaper.com

Received: 08-07-2020

Accepted: 14-08-2020

Dr. P Sai Vikranth MS ORTHO, Assistant professor, Department of Orthopedics, Mahavir Institute of medical sciences, Vikarabad Telangana, India
Corresponding Author: Dr. P Sai Vikranth MS ORTHO, Assistant professor, Department of Orthopedics, Mahavir Institute of medical sciences, Vikarabad Telangana, India

\section{A prospective study to know the outcome of midclavicular fractures treated with reconstruction / anatomical plate}

\section{Dr. P Sai Vikranth}

DOI: https://doi.org/ 10.22271/ortho.2020.v6.i4f.2362

\section{Abstract}

Background: Clavicle fractures are the most common injures occurring due to trivial fall on an outstretched hand, RTA or associated with poytrauma. Most of these fractures are treated in conservative methods by using clavicular braces and figure of 8 bandages which resulted in high rates of non $/ \mathrm{mal}$ union and functional diasability. The aim of the present study is to show the surgical management of midclavicular fracture with open reduction internal fixation (ORIF) with Recon/Anatomical Plates

Methods: The present study includes a total of 30 patients with mid-clavicular fractures operated with orif with recon/anatomical plates at mahavir institute of medical sciences and general hospital, vikarabad. Results: In a total of 30 patients operated with ORIF were 20 male and 10 were female patients. 22 cases had right clavicle fracture and 8 patients had left clavicle fracture.85\% of patients' sustained injury due to trivial fall, and 15\%RTA. All patients were admitted in emergency department and treated. According to Constant Murley scoring system excellent results were seen in 20 patients, good in 6 patients and fair in 2 patients and poor in 2 patients.

Conclusions: Mid-clavicular fractures treated with ORIF with plates showed excellent functional outcome, early mobilization, no pain and resume to his/her regular duties, when compared to conservative methods.

Keywords: Mid-clavicle fracture, Recon/Anatomical Plates, ORIF, Surgical Management, functional mobility

\section{Introduction}

Clavicle fractures are common Fractures occurring due $t$ trivial fall, RTA. Sometimes these fractures are associated with polytrauma. Overall these fractures accounts to $2.6-3 \%$ of all fractures ${ }^{[1]}$. These fractures mid-clavicle fracture accounts for $44 \%$ of fractures occurring around the shoulder ${ }^{[2]}$. Most of these fractures are treated with conservative methods like clavicular brace and figure of 8 bandage which results in non-union, mal-union, poor functional mobility ${ }^{[3]}$. The plates provide good anatomical fixation, stability, strength and early post-operative mobility. The aim of this study is to analyse the functional outcome of clavicular plate treated with ORIF. Plate fixation is the gold standard of operative methods ${ }^{[4]}$.

\section{Patients and Methods}

In this prospective study a total of 30 patients were included out of which 20 were male and 10 were female and 22 patients had right side injury and 8 patients had left side injury. The study has been conducted at Mahavir Institute of Medical Sciences And General Hospital, Vikarabad between march 2019 to march 2020 for a period of one year with regular follow-up. According to ALLMAN Classification the fractures were classified.

\section{Inclusion criteria}

1. Age $>20$ years

2. Closed fractures

3. Fractures classified according to ALLMAN Classification

4. No medical contraindications for surgery. 


\section{Exclusion criteria}

1. Age $<20$ years

2. Compound fractures

3. Pathological fractures

4. Un-displaced fractures

5. Associated head and nerve injury.

\section{Surgical technique}

All patients were operated in supine position with sand bag below the shoulder on the operated site under general anesthesia. Approach to the fracture is done by giving anterosuperior with transverse incision along the superior border of clavicle. The soft tissue released carefully and fracture site was approached. After reducing the fracture, the plate was fixed over the superior surface of the clavicle after reduction and fixed with screws on either side of the fracture. Interfragmentary screw was used in case of butterfly fragments. The wound was closed in layers and sterile dressing done and limb was supported in arm sling. (FIG 1).

\section{Post-operative protocol}

Post operatively all patients were kept on analgesics, antibiotics and operated limb was supported in arm sling. Regular dressings were done on $2^{\text {nd }}, 5^{\text {th }}$ and $10^{\text {th }}$ day and sutures/staples were removed on $12^{\text {th }}$ day. Patients were advised to use arm sling for a period of 15days followed by minimal mobilization at shoulder without weight lifting. ROM exercises were allowed from $5^{\text {th }}$ week post-operatively for 2 months. Regular $\mathrm{x}$-rays were taken at interval of $3^{\text {rd }}$ week, 2 months, 6 months and one year. (FIG 2).

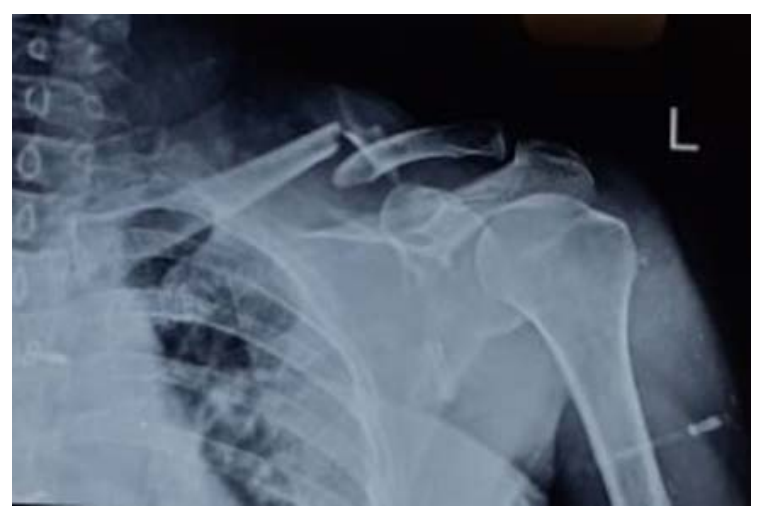

Fig 1: Preop Xray

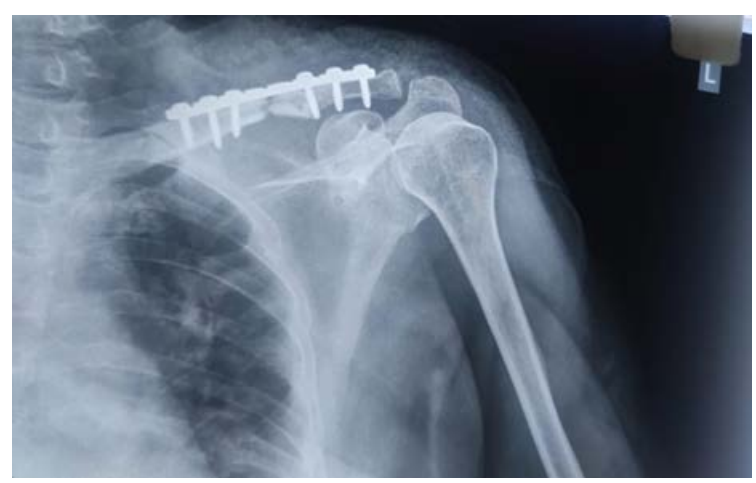

Fig 2: Post Op Xray

\section{Results}

Out of 30 patients operated, 20 were male and 10 were female patients. 22 patients had right side injury and 8 patients had left side injury. Out of 30 patients $85 \%$ sustained injury due to trivial fall and $15 \%$ due to RTA. Average age was 40 years. In this present study, all the fractures were classified according to ALLMAN System. All the patients were operated within one week post injury. In this 30 patients, 3 patients had associated fractures ( 2 had both bone forearm on same side and one had humerus fracture on same side). The results in this study showed 20 patients with excellent outcome, 6 patients had good results, with 2 patients each in fair and poor outcome. The poor outcome is due to implant failure due to fall post-surgery within the fracture healing period. All the results were analysed by percentage method.

Table 1: Age Distribution

\begin{tabular}{|c|c|}
\hline Age in years & Number of patients \\
\hline $20-30$ & 15 \\
\hline $31-40$ & 6 \\
\hline $41-50$ & 5 \\
\hline $51-60$ & 3 \\
\hline$>60$ & 1 \\
\hline Total & 30 \\
\hline
\end{tabular}

Table 2: Mode of Injury

\begin{tabular}{|c|c|c|}
\hline Mode of injury & No of patients & Percentage \\
\hline Trivial fall & 26 & $85 \%$ \\
\hline RTA & 4 & $15 \%$ \\
\hline Total & 30 & $100 \%$ \\
\hline
\end{tabular}

Table 3: Side of Injury

\begin{tabular}{|c|c|c|}
\hline Side of injury & No of patients & Percentage \\
\hline Right & 22 & $76 \%$ \\
\hline Left & 8 & $24 \%$ \\
\hline Total & 30 & $100 \%$ \\
\hline
\end{tabular}

Table 4: Sex Distribution

\begin{tabular}{|c|c|c|}
\hline Sex & No of patients & Percentage \\
\hline Male & 20 & $70 \%$ \\
\hline Female & 10 & $30 \%$ \\
\hline Total & 30 & $100 \%$ \\
\hline
\end{tabular}

Table 5: Results

\begin{tabular}{|c|c|c|}
\hline Outcome & No of patients & Percentage \\
\hline Excellent & 20 & $70 \%$ \\
\hline Good & 6 & $20 \%$ \\
\hline Fair & 2 & $5 \%$ \\
\hline Poor & 2 & $5 \%$ \\
\hline Total & 30 & $100 \%$ \\
\hline
\end{tabular}

\section{Discussion}

$75 \%$ of clavicle fractures are located in the mid-shaft region [5]. Most of these fractures are in the mid-clavicular region with displacement requiring internal fixation for better outcome ${ }^{[6]}$. The incidence of non-union in these fractures constitute around $1 \%{ }^{[7]}$. In general these fractures are traditionally treated with non-operative management which fail to heal in anatomical position and end up in non-union, fibrous union, mal-union with chronic residual pain ${ }^{[8]}$. More recent studies of mid-clavicular displaced fractures shows $50 \%$ rate of non- union ${ }^{[9]}$. Rowe reported non-union in 4 of 566 clavicular fractures in operative approach while compared Nowak et al. Which shown $46 \%$ of un-satisfied patients with symptoms of pain and restricted mobility and radiographic non-union [10]. Previous studies shown an evidence of un-satisfactory results in patients with clavicle fractures treated with conservative methods due to mal-union, weakness, and decreased ROM especially with overhead 
work. In our study with ORIF which showed excellent to good results in $26 \%$ patients with good union clinically and radiologically and better functional outcome for doing daily routine work without pain. The operative fixation of midclavicular fractures with plates shown good, stable and stiff fixation for better outcome ${ }^{[11]}$.

\section{Conclusion}

Mid-clavicular fractures treated with ORIF with plates showed excellent functional outcome, early mobilization, no pain and resume to his/her regular duties, when compared to conservative methods. Thus authors conclude ORIF gives best functional and radiological outcome in mid-clavicular fractures.

\section{References}

1. Postacchini F, Gumina S, De Santis P, Albo F. Epidemiology of clavicle fractures. J Shoulder Elbow Surg 2002;11:452-6.

2. Rickert AB, Hosalkar H, Pandya N, Namdari S. Displaced Clavicle Fractures in Adolescents: Facts, Controversies, and Current Trends. J Am Acad Orthop Surg 2013;21:1-2.

3. Robinson CM. Fractures of the clavicle in the adult epidemiology and classification, J Bone Joint Surg (Br) 1998;80:476-84.

4. Singh R, Rambani R, Kanakaris N, Giannoudis PV. A 2year experience, management and outcome of 200 clavicle fractures. Injury 2012;43(2):159-63.

5. Eskola A, Vainionpaa S, Myllynen P, Patlala H, Rokkanen P. Outcome of clavicular fracture in 89 patients. Arch Orthop Trauma Surg 1986;105:337-8.

6. Stanley D. Recovery following fractures of the clavicle treated conservatively. Injury 1988;19:162-4.

7. Rowe CR. An atlas of anatomy and treatment of midclavicular fractures. Clin Orthop 1968;58:29-42.

8. Althausen PL, Shannon S, Lu M, O’Mara TJ, Bray TJ. Clinical and financial comparison of operative and nonoperative treatment of displaced clavicle fractures. J Shoulder Elbow Surg 2013;22(5):608-11.

9. Hill JM, McGuire MH, Crosby LA. Closed treatment of displaced middle-third fractures of the clavicle gives poor results. J Bone Joint Surg Br 1997;79:537-9.

10. Nordqvist A, Petersson CJ, Redlund-Johnell I. Midclavicle fractures in adults: end result study after conservative treatment. J Orthop Trauma 1998;12:572-6.

11. McKee MD, Pedesen EM, Jones C, Stephen DJ, Kreder HJ, Schemitsch EH, et al. Deficits Following Nonoperative Treatment of Displaced Midshaft Clavicular Fractures. J Bone Joint Surg (Am) 2006;88(1):35-40. 